\title{
«Demasiada muerte innecesaria de jóvenes que no debieron haber muerto»: una conversación con José Manuel Valenzuela
}

\section{José Manuel Valenzuela entrevistado por Carles Feixa²}

Resumen (analítico): José Manuel Valenzuela Arce (Tecate, México, 1954) es doctor en sociología e investigador del Colegio de la Frontera Norte (Tijuana, México). Escritor prolífico, ha destacado en el análisis de las expresiones culturales juveniles en la frontera norte de México, desde su primer y pionero libro sobre pachucos, cholos, punks y chavos banda (;A la brava ése!, 1988), hasta su último libro sobre el juvenicidio (Trazos de sangre y fuego, 2019). La conversación repasa la trayectoria del autor, desde su infancia y juventud obrera en la capital de la frontera Norte, hasta su primera teorización del juvenicidio como muerte artera, pasando por su iniciación en la sociología, sus estudios sobre las culturas de frontera y su participación en las redes de investigación sobre juventud mexicanas e internacionales. El texto acaba con un epílogo con respuestas a distancia en torno a los efectos sobre las juventudes de la situación actual de pandemia.

Palabras clave: juventud, México, América Latina (Tesauro de Ciencias Sociales de la Unesco).

Palabras clave autores: Culturas juveniles, movimientos juveniles, juvenicidio.

\footnotetext{
${ }^{1}$ Investigador de El Colegio de la Frontera Norte, Tijuana (México). Correo electrónico: jmvalen@colef.mx

${ }^{2}$ Catedrático de Antropología Social en la Universitat Pompeu Fabra, Barcelona (Cataluña, España). Correo electrónico: carles.feixa@upf.edu
} 


\title{
«Too much unnecessary death of young people who should not have died»: A conver- sation with José Manuel Valenzuela
}

\begin{abstract}
José Manuel Valenzuela Arce (Tecate, Mexico, 1954) is doctor in sociology and researcher at the Colegio de la Frontera Norte (Tijuana, Mexico). Prolific writer, he has excelled in the analysis of youth cultural expressions on the northern border of Mexico, from his first and pioneering book on pachucos, cholos, punks and chavos banda (iA la brava ése!, 1988), to his latest book on juvenicide (Trazos de sangre y fuego, 2019). The conversation reviews the author's career, from his childhood and working-class youth in the capital of the northern border to his first theorization of juvenicide as a devious death, through his initiation in sociology, his studies on border cultures, and his participation in Mexican and international research networks on youth. The text ends with an Epilogue with remote responses about the effects on youth of the current pandemic situation.
\end{abstract}

Keywords: Youth, Mexico, Latin America (Social Sciences Unesco Tesaurus).

Autors keywords: Youth cultures, Youth movements, juvenicide.

\section{«Muita morte desnecessária de jovens que não deveriam ter morrido»: uma conversa com José Manuel Valenzuela}

Resumo (analítico): José Manuel Valenzuela Arce (Tecate, México, 1954) é doutor em sociologia e pesquisador do Colegio de la Frontera Norte (Tijuana, Mexico). Escritor prolífico, destacouse na análise das expressões culturais juvenis da fronteira norte do México, desde seu primeiro e pioneiro livro sobre pachucos, cholos, punks e chavos banda (¡A la brava ése!, 1988), até seu último livro sobre juvenicídio (Trazos de sangre y fuego, 2019). A conversa revisa a carreira do autor, desde sua infância e juventude operária na capital da fronteira norte até sua primeira teorização do juvenicídio como uma morte tortuosa, passando por sua iniciação em sociologia, seus estudos sobre culturas fronteiriças e sua participação em redes de pesquisa sobre a juventude mexicana e internacional. O texto termina com um Epílogo com respostas remotas sobre os efeitos da atual situação de pandemia na juventude.

Palavras-chave: Juventude, México, América Latina (Tesaurus de Ciencias Sociais da Unesco). Palavras-chave autores: Culturas juvenis, movimentos juvenis, juvenicídio. 


\section{Introducción}

José Manuel Valenzuela Arce (Tecate, México, 1954) es doctor en sociología e investigador del Colegio de la Frontera Norte. Escritor prolífico, ha destacado en el análisis de las expresiones culturales juveniles en la frontera norte de México, desde su primer y pionero libro sobre los pachucos, cholos, punks y chavos banda (;A la brava ése!, 1988), hasta su último libro sobre el juvenicidio (Trazos de sangre y fuego, 2019). Descubrí la primera publicación durante mi primera estancia en México, en 1991, poco antes de iniciar mi trabajo de campo en Ciudad Nezahualcóyotl, leyéndolo con avidez. Constaté significativos paralelismos con mi propia trayectoria teórica — de Gramsci a los cultural studies-y etnográfica - de la etnohistoria a las historias de vida-. No coincidimos personalmente hasta 1998, en el famoso encuentro de Ixtapan de la Sal organizado por José Antonio Pérez Islas, para reflexionar sobre la Encuesta Nacional a la Juventud. En zooo le invité a la Universidad de Lleida a un encuentro con el grupo de trabajo de Juven-

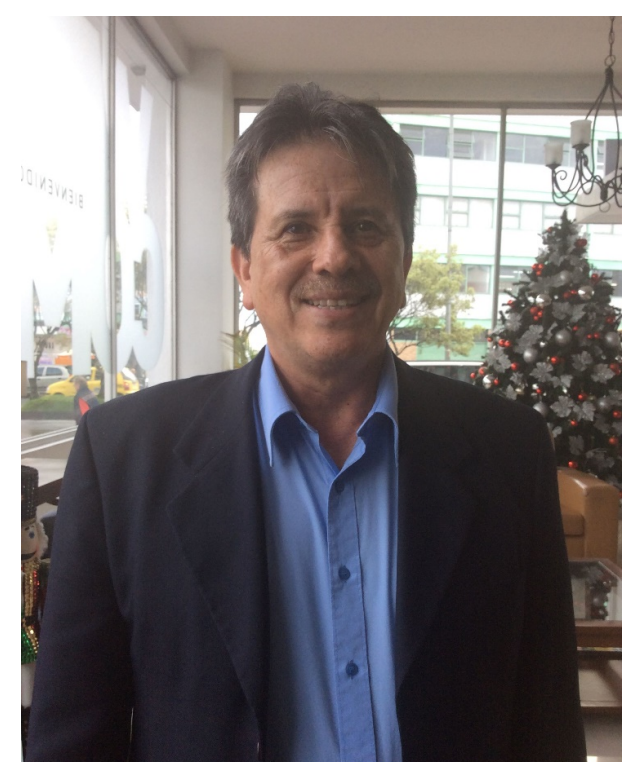

José Manuel Valenzuela durante la entrevista (Manizales, 21-11-2014). Foto (C Carles Feixa. tud de Clacso que reunió a la flor y nata de la juvenología latinoamericana (Valenzuela, 2002). Luego él me invitó a Tijuana a otros eventos y por el camino coincidimos en varios países latinoamericanos y en varias publicaciones colectivas.

La presente entrevista tuvo lugar en tres partes (aunque esta versión se basa en la segunda). La primera transcurrió en octubre de 2014 en La Plata (Argentina) durante el congreso Jumic organizado por Florencia Saintout; José Manuel tenía una gripe muy fuerte y su estado no era el mejor para responder. La segunda tuvo lugar al cabo de un mes en Manizales (Colombia), durante la II Bienal de Infancias y Juventudes, en la que compartimos una mesa memorable sobre el juvenicidio, que sería la semilla del libro colectivo sobre el tema coordinado por él (Valenzuela, 2016). La tercera parte tuvo lugar en Ciudad Juárez (México) en marzo de 
2016, en otro encuentro sobre las juventudes en fronteras. La conversación repasa la trayectoria del autor, desde su infancia y juventud obrera en la capital de la frontera norte, hasta su primera teorización del juvenicidio como muerte artera, pasando por su iniciación en la sociología, sus estudios sobre las culturas de frontera y su participación en las redes de investigación sobre juventud mexicanas e internacionales. El texto acaba con un epílogo con respuestas a distancia en torno a los efectos sobre las juventudes de la situación actual de pandemia.

\section{Muy joven todavía era declamador de poesía}

Carles Feixa (C. F.): Estamos en Manizales, el viernes 21 de noviembre de 2014, con José Manuel Valenzuela. La idea es hacer una especie de historia de vida, personal e intelectual, que ayude a los lectores a ubicarte como una persona que se interesó primero por la juventud como joven, después investigó la juventud y que ha hecho algunas aportaciones a su estudio. Primero preséntate.

José Manuel Valenzuela (J. M. V.): Mi nombre es José Manuel Valenzuela Arce. Actualmente soy investigador del Departamento de Estudios Culturales de El Colegio de la Frontera Norte y secretario general académico. Nací en la ciudad de Tecate, Baja California, un pueblo fronterizo que entonces tenía escasos cinco mil habitantes, una población muy interesante, donde el corazón económico del pueblo era la cervecería Cuauhtémoc, una gran empresa muy importante donde se elaboraban las cervezas Tecate, Bohemia, Carta Blanca y Noche Buena, y era el corazón no solo económico sino también, en muchos sentidos, social. La cervecería marcaba los ritmos con su potente silbato que se activaba a las 6 a. m., 6.15 a. m., 7 a. m., 12 m., 1 p. m., 4 p. m. y 9.30 p. m., para definir y organizar la rutina del pueblo, la entrada a la escuela, la salida del trabajo, la hora de la comida, el tiempo de recogimiento. El silbato de la cervecería competía con el tañido sacro de la campana de la iglesia que convocaba a sus feligreses y marcaba otras rutinas en la cotidianeidad del pueblo.

C. F.: Tiempo de la industria y tiempo sacro...

J. M. V.: Tecate es un pueblo fronterizo que limita con otro Tecate, al que llamamos Tecatito, en California, Estados Unidos, que apenas tenía doscientos habitantes. Tecate se encuentra en el noroeste mexicano, entre California, Estados Unidos y Tijuana. Mi infancia y juventud trascurrió ahí, en una familia muy numerosa; fuimos catorce hermanos y hermanas; mi hermano mayor murió muy pequeñito; quedamos nueve hermanas, cuatro hermanos, mis padres y mi abuela. Mi padre fue empleado de la cervecería y yo ingresé a los quince años a laborar allí como trabajador eventual, mientras terminaba la escuela preparatoria; combinaba las actividades de la escuela con el deporte y el trabajo. 


\section{F.: ¿En qué año naciste?}

J. M. V.: Nací el primero de agosto de 1954, pero en todos mis documentos oficiales, por un error en la elaboración del acta de nacimiento en el Registro Civil, soy del 3 de agosto de 1954. Muy joven todavía era declamador de poesía, ganaba concursos y esas cosas; me sabía muchos poemas tradicionales. El caso es que yo quería estudiar; era hijo del milagro mexicano, época donde uno, como obrero, podía soñar con estudiar una carrera y yo quería ser ingeniero petrolero. Una muchacha de Tecate conoció a un joven que cantaba en una hostería de Ciudad de México, donde tocaban canciones y declamaban poemas; un lugar bohemio. Este joven fue a Tecate a visitarla y ella organizó una reunión donde yo declamé, y él me dijo que podría trabajar declamando en la hostería. Solicité ingresar a la carrera de ingeniero químico metalúrgico en la Universidad Nacional Autónoma de México (Unam) y me fui a la Ciudad de México. En realidad, nunca trabajé en la hostería pues mi madre se opuso. Finalmente, llegué a la Ciudad de México en 1973, en un período definido por vientos de cambio muy fuertes; se vivía la secuela represora pos-68 y pos-71. Durante las gestiones de los expresidentes Días Ordaz (1964-1970) y Luis Echeverría (1970-1976) se dieron las brutales represiones en contra de los estudiantes mexicanos como la masacre del 2 de octubre de 1968 en Tlatelolco y el sangriento jueves de corpus del 10 de junio de 1971, además de la desaparición de muchos jóvenes que luchaban en contra del sistema. En ese momento había un clima político y social sumamente represivo y en ese contexto se dio el golpe de Estado en Chile que a mí me impactó mucho. Yo no tenía formación política, pero tenía una conciencia humanista. Ya en la universidad, estudiando minerales, fórmulas, integrales y diferenciales, me dije, «qué estoy haciendo aquì, y en ese momento me involucré con un grupo clandestino que se llamaba Grupo Comunista Internacionalista; en realidad todos los grupos de izquierda eran clandestinos, pues estaban prohibidas las organizaciones políticas. Empecé a participar en la organización de obreros, por supuesto, como ya señalé, de forma clandestina porque en México no se permitía la participación en organismos políticos y en las fábricas había guardias blancos cuya función era reprimir los intentos de organización de los trabajadores. La alternativa que planteábamos y por la cual luchábamos era la organización del proletariado como vanguardia del cambio social.

En ese contexto y desde mi experiencia como obrero de industria, me daba cuenta que la mayoría de las y los colegas tenían más experiencia de acción estudiantil y universitaria que laboral, por lo que yo me involucré más en la organización de trabajadores. Así le dediqué varios años de mi vida y, a finales del 79 regresé a la ciudad de Tijuana. Había nacido mi hijo Pável y me fui a buscar otras opciones personales. El caso es que llegué allí y encontré trabajo como obrero en la única compañía telefónica que había en el noroeste mexicano, una empresa muy 
grande. Al mismo tiempo, participaba en el comité directivo de la organización política a la cual pertenecía. En ese tiempo participaba como orador en algunos mítines y hacía parte de los movimientos de solidaridad con El Salvador. Rápido me identificaron; el jefe de personal me mandó a llamar y me dijo: «Usted es un agitador profesional y no puede trabajar aquí»; me corrieron. Empecé a buscar opciones de trabajo en la maquila, pero no me contrataban, no me aceptaban; estar desempleado no era una opción. En ese momento había un movimiento barrialpopular muy visible de jóvenes que se autoidentificaban y a quienes se reconocía como «cholos». Todo el mundo hablaba de los cholos desde posiciones lejanas, estereotipadas; los consideraban el enemigo público número uno, el grupo más violento. La gente les temía, los medios de comunicación les atacaban desde perspectivas criminalizantes. En ese momento se dio una campaña para legalizar las redadas con el argumento de que eran necesarias para combatir a los cholos. En ese mismo contexto de la lucha contra los cholos se planteó un congreso anticholo y nosotros, como organización política, sabíamos que debíamos oponernos a esas estrategias de criminalización de los jóvenes. Por ello decidimos participar para oponernos, pero luego surgió la pregunta: ¿qué son los cholos?

Yo me propuse para investigar al cholismo y empecé a hacer trabajo en los barrios cholos con los muchachos, para poder tener una opción crítica en el congreso anticholo. En ese tiempo había ocurrido una agresión muy grande contra la gente que vivía en lo que ahora es la zona más rica de Tijuana, la zona del Río, donde solo había basureros y yonques. Ahí vivía gente muy pobre; gente que a lo largo de los años construyó allí su esperanza habitacional, pero despertaban mucha codicia pues eran terrenos planos, cercanos a la frontera y con muy alto valor comercial. El alto valor de los terrenos despertaba la codicia de diversos actores inmobiliarios, políticos y empresariales de todos los niveles; había mucha codicia y a toda costa querían desalojar a los colonos para apropiarse de esos terrenos. Hubo varios intentos de desalojo; el primero de ellos fue en 1959, con el gobernador Braulio Maldonado; el segundo se dio en 1974 con Milton Castellanos, donde fue desalojada una parte de los colonos y se asesinó a un habitante de esa zona (a la que se le llamaba Cartolandia porque las casas eran de cartón). En 1979, aprovechando las intensas lluvias que se presentaron, las máquinas entraron y derribaron las casas de los colonos que seguían en zona del Río, lo cual provocó mucho enojo y se formó el Comité Unión de Colonos Urbanos de Tijuana, Asociación Civil. Hubo mucha radicalización en la gente y el movimiento urbano popular se convirtió en el principal actor político colectivo de Baja California. El zo de enero de 1980 en la madrugada el Gobierno abrió las compuertas de la presa sin avisarle a la gente y el agua amontonada mató a mucha gente, entre ellas a la familia Ruelas Solís, donde seis de los siete miembros de la familia murieron, incluidos cuatro niños; los cuerpos fueron arrastrados por el agua hasta el condado de San Diego, en Estados Unidos. 
En ese momento, desde la organización política en la que participaba, teníamos un trabajo con los dirigentes de esos movimientos y yo estaba cercano a eso, acompañando al movimiento urbano popular, en barrios y colonias, espacios donde vivían los cholos.

\section{Inicié como bibliotecario}

C. F.: ¿Con qué metodologías documentabas?, ¿era algo intuitivo?

J. M. V.: No tenía un proyecto académico. Cuando me desemplearon en 1981, me puse a buscar trabajo en bibliotecas. En la Ciudad de México había trabajado en diferentes empleos: fui paquetero en una línea de autobuses de segunda categoría; office boy en una compañía telefónica; trabajé de varias cosas, pero finalmente encontré un trabajo como bibliotecario en el Colegio de Ciencias y Humanidades de la Unam. Buscando trabajo en las bibliotecas de Tijuana, una bibliotecaria chilena me recomendó que solicitara empleo en una biblioteca de una institución que estaba por crearse. Ahí me hicieron un examen e inicié como bibliotecario; era una institución que estaba por nacer, no había nada, así que me tocó hasta pintar los anaqueles. Un día, hablando con la directora de la biblioteca, me enteré que iban a llegar de Ciudad de México unos investigadores y que ese sitio iba a ser el Centro de Estudios Fronterizos del Norte de México, lo que hoy es El Colegio de la Frontera Norte. Yo ayudaba en la biblioteca y sacaba fotocopias para los investigadores; pero, dada mi condición de bibliófilo y mi formación política, siempre hubo un trato respetuoso. Al mismo tiempo, realizaba el trabajo de investigación con los cholos y estaba vinculado con actoras y actores del Movimiento Urbano Popular y con los movimientos de solidaridad con las luchas centroamericanas.

Me involucré a fondo en el trabajo comunitario con los cholos y pasaba mucho tiempo en los barrios. Un día, el precursor y presidente de la institución, Jorge Bustamante, me llamó y me propuso que participara en la convocatoria de maestría en Desarrollo Regional, para lo cual, obviamente, debía terminar una licenciatura. El asunto es que yo había abandonado la universidad en Ciudad de México, aunque después tomé unos cursos de Economía Política en un sistema abierto de la Unam, pero lo dejé al regresar a Tijuana. En ese periodo ocurrió la ruptura de la huelga en la Universidad Autónoma de Baja California (UABC). Esto me involucraba, porque participé, desde el CCH y la organización política en la que militaba en la lucha para la conformación del Sindicato Único de Trabajadores Universitarios. No tenía un papel protagónico, pero presencié cuando fueron a romper la huelga, ahí en mi pueblo. Quienes iban a romper la huelga eran los obreros de la cervecería. Entonces nadie me tocaba; todos nos conocíamos. En Mexicali, la ruptura de la huelga fue a balazos; en Tijuana hubo golpes, golpearon muy feo a los huelguistas; pero en Tecate no hubo agresiones. Estábamos todos ahí, dentro de 
las instalaciones; una historia que pareciera sacada de un cuento, como al inicio de Los astros no se equivocan, de Benedetti. Por ello, cuando el presidente de la institución me propuso el desafío, no pude ingresar a la UABC. Entré al programa de maestría y, simultáneamente, concluí de manera autodidacta la licenciatura en la Universidad de Sonora, institución que no tenía sistema abierto, pero me permitieron avanzar mediante exámenes y trabajos finales. Aprovechando que había estado acompañando a los cholos desde mi actividad política, transformé esa experiencia en un libro que se llama iA la brava ése! (Valenzuela, 1988), que lo escribí con grado formal de preparatoria y ese mismo libro lo presenté como tesis para obtener la licenciatura.

En la maestría, presenté como tesis un libro que se llama Empapados de sereno: el movimiento urbano popular en Baja California (Valenzuela, 1991). Así se dio la articulación entre el acompañamiento político-comunitario y mi proyecto académico; podría decir que mis dos primeros libros abrevan de manera directa del acompañamiento social. Luego me fui a estudiar el doctorado al Colegio de México, y ahí trabajé una tesis que se llama El color de las sombras: chicanos, identidad y racismo (Valenzuela, 1998). A finales de los ochenta ya había publicado estos libros y ya estaba más cercano a lo que fue un núcleo de personajes afines que hacían investigación sobre juventud. Muy temprano en los ochenta (por allá en el 82) conocí a José Antonio Pérez Islas, y por esa época empecé a publicar artículos de temas de cholismo, consolidando mi interés en los estudios de juventud. Entonces, transitamos de la prevalencia de un ensayismo y crónicas sobre las y los jóvenes hacia la investigación académica. Las tradiciones de crónica y ensayo nos ayudaron a entender las vidas y culturas juveniles y fueron el antecedente del surgimiento de un campo de estudios sobre juventud que se nutrió de las importantes obras y textos de Carlos Monsiváis, Elena Poniatowska, José Agustín, Parménides García Saldaña y Víctor Roura. En el Centro de Estudios Fronterizos (hoy El Colef) formamos un Departamento de Estudios Culturales, con una fuerte impronta gramsciana. Gramsci era muy destacado en la interpretación de los movimientos sociales y el movimiento urbano popular era muy fuerte en ese momento, no solo en Tijuana, sino en México y en América Latina.

A inicio de los años ochenta, conocí a Carlos Monsiváis, con quien tuve una muy importante amistad; lo llevé a los barrios cholos y quedó muy impresionado; él escribió algo sobre el cholismo en su libro Los rituales del caos. En la segunda mitad de los ochenta se fueron consolidando redes académicas de juvenólogos y conocí a otros investigadores que habían realizado trabajos muy sólidos, entre ellos un personaje catalán de nombre Carles Feixa. Yo ya conocía a Maritza Urteaga y a José Antonio Pérez Islas, quien, desde El Consejo Nacional de Recursos para la Atención de la Juventud, participaba de manera muy activa como organizador e inspirador de ese acercamiento entre estudiosos y estudiosas de los jóvenes. Fue un periodo definido 
por una amplia e intensa reflexión e investigación sobre las juventudes, especialmente las precarizadas en la llamada década perdida de los años ochenta, y se conformó un campo de estudios sobre juventud. En un primer momento, parte de la discusión se dio mucho desde una suerte de populismo académico, donde se legitimaba la investigación realizada desde una condición de clase más cercana a los chavos banda o a los cholos. Obviamente no se trataba de exhibir las biografías para ver quién estaba más cerca a los sectores proletarizados. En mi caso, desde mis primeras investigaciones en los albores de los ochenta y en iA la brava ése!, existe una perspectiva gramsciana e interpretaba al movimiento urbano y al cholismo como expresiones de las culturas populares.

Ya en los noventa podemos decir que se había consolidado un campo de estudios de juventud en América Latina y, de manera destacada, en México, además de los ya señalados. A inicios de esa década conocí a Rossana Reguillo, quien recién había publicado su iluminador libro, En la calle otra vez, y se realizaron trabajos muy importantes por parte de nuevos investigadores como Alfredo Nateras y Néstor García Canclini, figura canónica de los estudios culturales, quien hizo un giro en sus estrategias investigativas estudiando procesos juveniles; en Argentina estaban Sergio Balardini y Margulis; de Brasil conocía los trabajos de Alba Zaluar, Zuenir Ventura y Manoel Ribeiro; en Colombia estaba Alonso Salazar, Germán Muñoz, Jesús Martín Barbero, Fulvia Márquez, los grupos de la Corporación Región, el Instituto Popular de Capacitación. En fin, había una importante perspectiva latinoamericana e iberoamericana que, por cierto, no era muy reconocida en los libros sobre la historia social de la juventud. Tampoco aparecían los jóvenes indígenas, por ejemplo. En mi caso, no solo hacía investigación sobre jóvenes y culturas juveniles, sino que también estudiaba temas de fronteras, identidades, movimientos sociales y culturas populares, los que han sido ejes centrales en mi trabajo.

\section{De juvenólogo a fronterólogo}

C. F.: ¿Tiene algo que ver en tu interés por la frontera tu interés por la juventud, que es también una frontera vital biográfica?

J. M. V.: Total; de hecho cuando yo empecé a trabajar el tema del cholismo, una de las primeras características que marcaron mi investigación fue la condición fronteriza. Trabajé el cholismo en ambos lados de la frontera, vinculado a la historia de la población mexicana chicana, chicana y fronteriza, pero recuperando gran parte de los elementos simbólicos definitorios del perfil cultural de lo mexicano, que fueron recreados y reinventados como referentes de resistencia social, política y cultural por el Movimiento Chicano. Empecé a trabajar el cholismo, pero me tocó la última parte de los pachucos, el primer gran movimiento juvenil trans- 
fronterizo; entonces los trabajé de forma conjunta. El pachuquismo fue el primer gran fenómeno cultural transfronterizo y los cholos fueron sus herederos. El segundo eje es el feminismo y lo incorporé desde mi primera incursión en los barrios, al darme cuenta de la gran diferencia en las rutinas y poderes entre hombres y mujeres. Mi formación política incluyó las discusiones feministas al parejo de la conformación de las organizaciones feministas en México, algunas de ellas muy cercanas a nuestra perspectiva. El Departamento de Estudios Culturales lo dirigía Amelia Malagamba, quien era feminista, así que formamos un Departamento donde en el feminismo, las fronteras, el arte, la cultura popular, el racismo y las culturas juveniles fueron referentes centrales. Pero como el debate de los chicanos pasaba por el tema étnico nacional, entonces nuestro trabajo incluyó la reflexión-acción sobre fronteras étnicas, fronteras nacionales, fronteras juveniles, fronteras de género y fronteras generacionales. Esto fue lo que marcó el inicio de mi trabajo académico.

C. F.: Más que juvenólogo eres fronterólogo.

J. M. V.: Así es.

C. F.: Volviendo a tu primer libro - iA la brava ése! - como te he explicado, lo descubrí por casualidad en una librería cerca del Zócalo [de la ciudad de México], en el año go o 91, en mi primer viaje a México. Iba allí después de mi doctorado intentando investigar algo semejante; había investigado en Cataluña las tribus urbanas, pero sin tener ni idea que podía existir algo semejante (en México); más bien iba con los estereotipos de la juventud indígena. Y cuando los parientes mexicanos de mi esposa, procedentes del exilio republicano español, me empezaron a hablar de los chavos banda, me fascinó; pero tu libro fue, yo creo, el primero o el segundo que encontré que hablaba del tema; el otro era la visión de las bandas delincuentes, criminales: ¿Que transa con las bandas?, de Jorge García-Robles (1985).

J. M. V.: Sí, para entonces ya se habían realizado algunas interpretaciones. Lo de Jorge básicamente son entrevistas con chavos banda, desde las cuales construyó un relato cargado de estampas límite de esos jóvenes, pues si le pones el micrófono a un muchacho y le dices que te cuente su vida, obviamente él te va a destacar los aspectos relevantes que él considera que te pueden impresionar: «Maté», «violé»; es una historia sensacionalista. Entonces tienes que estar más tiempo en los barrios y observar-vivir sus rutinas o parte de ellas; ellos tienen otros tiempos, tienen otro tipo de actividades, tienen otras rutinas; no todo se reduce a escándalos o a actividades realizadas en el límite. El otro tema que era importante en ese momento era el de una perspectiva que se apropiaba de manera laxa de algunas categorías del marxismo desde la cual se planteó que los chavos banda eran el nuevo soviet del pueblo. Yo ya había trabajado con los cholos, los punk, los rockers; había trabajado parte de los movimientos hip hop y había 
trabajado el movimiento de los pachucos y también me interesé en los chavos banda. En 1981 el periódico Uno más uno publicó un cintillo que decía: «Temblamos de hambre y de frío, odiamos a todos, incluso a nosotros mismos; mejor morir pronto», y firmaban Los Panchitos. Yo trabajé con chavos banda en Guadalajara y Ciudad de México, pero, más que todo, con la vertiente de los PND, quienes recuperaron el grito de The Clash tras la muerte de Sid Vicious de Sex Pistols: «Punks Not Dead». El chavo banda era un concepto sombrilla estereotipado que tenía múltiples rutinas, condiciones; yo trabajé más con la parte punk de este movimiento.

C. F.: ¿En qué barrio de Ciudad de México?

J. M. V.: Trabajé en distintas colonias y barrios populares, pues los punk eran una suerte de nómadas urbanos. Recuerdo algunos personajes como Chucho Punk, Chucho Mafer, El Ganso, La Zappa, El Cabezón, El Iti..., eran muchos. En ese momento había un acercamiento entre los PND y los punk tijuanenses. Los punk trajeron el tema del tatuaje, pero lo curioso es que los diseños que traían eran los tatuajes de los cholos; entonces se veían muchos punk con tatuajes acholados; eran muy interesantes. Yo hice trabajo con ellos a mediados de los años ochenta. El cholismo lo empecé a trabajar en el año 81 y el libro jA la brava ése! se publicó en el 88; tardó mucho en ver la luz por razones ajenas a mí, pero finalmente salió.

\section{Conversar con los muchachos}

C. F.: ¿Cuál fue tu método en esa primera investigación?

J. M. V.: Tuvo que ver mucho con las conversaciones con los muchachos, porque a mí lo que me interesaba era recuperar sus testimonios de abuso policial, los testimonios que mostraran que el cholo no solo era un delincuente, y poder enfrentar las leyes represivas que querían imponer. Quería documentar todo eso y fue importante que un compañero procedía de un barrio famoso y sus hermanos eran de los cholos más pesados de Tijuana; a través de ellos incursioné en los barrios; obviamente yo jamás fui cholo ni pretendí parecerlo. Yo llegaba con una cámara a un barrio totalmente desconocido para mí y me ponía a tomar fotos de murales y «placazos» (grafitis) y agarraba aire porque sabía que en unos momentos iba a estar totalmente rodeado y que solo tenía unos segundos para reaccionar y «berrearlos», convencerlos, explicarles el motivo de mi presencia en su territorio, y me fue muy bien. Varios años estuve trabajando con cholos; trabajé todos los Estados de la frontera, en Sinaloa, en Los Ángeles, Estados Unidos. También acompañé a los punk en Tijuana, Guadalajara, Ciudad de México y Río de Janeiro, Brasil; con chavos banda en Ciudad de México y Guadalajara y con funkys brasileños. 
Después, al terminar mi doctorado, me ofrecieron hacer una estancia de investigación en Brasil, invitado por Heloísa Buarque de Holanda, de la Universidad Federal de Río de Janeiro, porque le interesaba mucho una mirada sobre el tema funky en las favelas, e hice el libro Vida del barro duro (Valenzuela, 1997). Flavio Negão era el bandido más buscado de Brasil y el título del este libro viene de él; no lo dijo literal, pero decía que la vida en las favelas de la gente pobre era muy difícil, que era como el barro duro. Entonces trabajé con esta parte del movimiento funky en Río de Janeiro en los años 1993 y 1994. Ahí mismo trabajé movimiento punk y el movimiento afro, y entrevisté a algunas personas del movimiento afrobrasileño que estaban documentando las chacinas de La Candelaria; la masacre de niños fuera de La Catedral: niños que dormían afuera de La Catedral, les permitían dormir allí, pero no adentro, y en aquella época los comerciantes a través de un grupo que se llamaba Cavalos Corredores, dirigido por un general Laranjeiras, se dedicó a esta limpieza social de niños. Un policía brasileño decía que los niños eran como las ratas y que entre más rápido las mataras, era mejor. A los niños y niñas de La Candelaria los asesinaron mientras dormían; eso se encuentra en el libro de Vida del barro duro.

Posteriormente el tema de jóvenes para mí fue como la canción de Un viejo amor, que «ni se olvida ni se deja», y a veces creía que iba a cerrar la ventanilla sobre el tema juvenil, pero surgían otros movimientos, algunos de clase media, como los Emos o Nortec. A la gente de Nortec la conocí a través de una amiga en común. Me pareció sumamente sugerente su propuesta y comencé a trabajar con ellos; de manera muy rápida se volvieron famosos. Los jóvenes de Nortec y sus propuestas son muy interesantes. Ellos tenían redes en el mundo mucho más amplias que las mías; todos son bilingües, estudiaron en Estados Unidos y tenían un uso tecnológico impresionante, que era necesario para su propuesta de música electrónica. Con Nortec trabajé otras perspectivas; al inicio, como seguramente te pasó a ti, cuando trabajé con los cholos, ellos no tenían celulares y la mayoría tampoco tenían teléfonos fijos en casa; para ir con ellos, tenía que llegar patrullando en mi picop, esperando encontrar a alguno y atendiendo a las sombras desde donde podían estar observando, hasta que escuchaba una voz, un silbido, aparecían de repente o los encontraba en la esquina.

Coordiné con Gloria González un libro que se llama Oye cómo va: recuentos del rock tijuanense (Valenzuela \& González, 1999), que contiene textos y entrevistas con algunas figuras emblemáticas, como Carlos Santana, Javier Bátiz, Julieta Venegas; grupos que han sido muy importantes como Solución Mortal, Tijuana No (de Tijuana) y entrevistas con personajes muy reconocidos que tenían una relación muy cercana con Tijuana, como son Manu Chau y Maldita Vecindad, especialmente Roco y Pacho. Después de 30 años de hacer estudios con jóvenes, hice una recopilación de lo que se ha hecho y me gustó mucho ese ejercicio porque te coloca en 
una condición interesante de repensar lo que hiciste desde una condición reflexiva, como una memoria histórica crítica sobre tu propio relato. También trabajé el libro Tropeles juveniles (Valenzuela, 2014) y Sed de mal (Valenzuela, 2012); creo que este es un libro importante porque es un trabajo sobre el feminicidio, el juvenicidio y los temas de frontera, tratando de entender cómo fue que llegamos a esos escenarios de muerte artera y doliente, esas necrozonas. Para entender el fondo de este tipo de problemáticas investigué el contexto social y las dinámicas que definen a la condición fronteriza.

En alguna ocasión quise hacer una historia social de la frontera, pero contada a través de los relatos inscritos en el corrido y la tradición popular. El corrido tuvo una presencia importante en la segunda mitad del siglo XIX, pero irrumpió con enorme fuerza a inicios del XX, como recurso de una población iletrada, una población que en su gran mayoría no sabía leer ni escribir, pero podía contar cantando sus historias, sus tragedias, sus esperanzas. Yo quise contar desde los corridos la historia social de la frontera, pero, al llegar a los años sesenta y setenta, el tema del narco se visibilizó de manera impresionante, y ya en los ochenta y noventa es avasallante la producción de corridos que aluden a los entramados del narcotráfico. El libro que derivó de este estudio se llama Jefe de jefes: corridos y narcocultura en México (Valenzuela, 2002), publicado por Casa de Las Américas de Cuba, en 2001, y por Random House Mondadori. También publiqué un libro que se llamó Nuestros piensos: culturas populares de la frontera México-Estados Unidos (Valenzuela, 1998b). Parece que los ejes de mi trabajo son evidentes: siempre aparece la cultura popular, el tema de jóvenes, el tema de frontera, el tema de identidad y música, pero no desde una mirada musicológica (no soy musicólogo), aunque a Jefe de jefes se le reconoció con el premio internacional de musicología Casa de Las Américas de Cuba, en 2001. Yo trabajo los usos sociales de la música, porque todo movimiento social viene acompañado de expresiones musicales, de una experiencia que se cuenta de forma rítmica, que se cuenta a través del rap, que se cuenta a través de un corrido, que se cuenta a través de la exaltación y los decibeles del heavy metal, que se cuenta a través de las letras radicales con cuestionamientos sociales del hardcore o del rock politizado y crítico, al estilo de Joan Báez, Bob Dylan, Jefferson Airplane, Frank Zappa o algunas canciones de los Beatles, especialmente las de John Lennon, hasta nuestros Caifanes, Maldita Vecindad, Tijuana No, entre muchos otros.

Todo eso nos da un panorama muy amplio de experiencias de movimientos juveniles; y ya después del 81 para acá podemos decir que son treinta y tantos años en los que sigo sorprendiéndome con la enorme capacidad de reinvención en las identidades juveniles y en la definición de sus formas de participación política, como tú lo has venido trabajando y como lo vienen trabajando Rossana Reguillo, Germán Muñoz, Alfredo Nateras y otros más. Estamos ahora en 
una nueva dimensión donde atrae todo lo que tiene que ver con las nuevas formas de experiencia colectiva, de las mediaciones del sentir en las experiencias colectivas, de las nuevas formas y sentidos de estar juntos, el uso de nuevos recursos, como los dispositivos tecnológicos que tanto tú has trabajado como forma de generar los procesos comunicativos, de amistad, etc. Pero también observamos la importante presencia y visibilidad de distintos movimientos juveniles en el mundo.

C. F.: Los Tigres del Norte te invitaron a presentar un disco suyo, ¿no?

J. M. V.: Cuando estaba haciendo el libro Jefes de jefes mandé dos cartas solicitando una entrevista y no me contestaron, y yo no soy muy aferrado, cuando no me abren la puerta no entro. Sin embargo, cuando salió el libro Jefe de jefes, título retomado de un corrido de Los Tigres del Norte, le fue muy bien; es un libro que ganó el premio Casa de Las Américas, como lo señalabas, pero al mismo tiempo lo distribuyó Random House, lo cual implicó su amplia distribución; además, salió una versión en Cuba. Random House construyó un fuerte proceso de difusión y promoción con entrevistas en radio, prensa y televisión, y tuve una entrevista con Carmen Aristegui y Javier Solórzano en un programa que se llamaba Círculo rojo; al día siguiente salí muy temprano a Tijuana y, al llegar a casa, estaba sonando el teléfono y era una invitación de Los Tigres del Norte para presentar el disco que recién habían grabado, titulado La reina del sur, un disco con un corrido basado en la novela de Arturo Pérez Reverte, quien hizo su novela sobre el tema del narcotráfico con referencias a México y a España. El caso es que acepté la invitación y fue una experiencia alucinante. Los Tigres del Norte son personas fuera de serie, con una enorme capacidad de mantener los pies sobre la tierra; es impresionante, no sé cómo no enloquecen. Es gente muy sencilla y sensible. Creo que su éxito deriva de su capacidad de pulsar e interpretar los sentimientos del pueblo. Fue un performance muy impresionante; estaba lleno el Centro Cultural Siqueiros de la Ciudad de México. Al final, un periodista preguntó a Jorge Hernández si ya podía revelar la personalidad del jefe de jefes y, en un desliz preocupante, contestó que el jefe de jefes era el Doctor Valenzuela. Yo me puse de pie haciendo aspavientos de que eso no era cierto y todo se aclaró en medio de la risa incontinente de los periodistas.

\section{Demasiada muerte innecesaria de jóvenes que no debieron haber muerto}

C. F.: Esta mañana hemos compartido una mesa aquí en Manizales, hablando de juvenicidio; al final nos han aplaudido a rabiar, aunque fue una sesión muy dura. ¿Cómo valoras el juvenicidio a la luz de tu libro de hace dos años, Sed de mal, y de los sucesos recientes? 
J. M. V.: Yo creo que se ha profundizado mucho. Cuando escribí ese libro su título original era Sed de mal: feminicidio, juvenicidio y exclusión social, pero aún cuando está desarrollado o trabajado el juvenicidio, pensé que no tenía el mismo peso que el feminicidio y al final decidí ponerle el subtítulo de feminicidio, jóvenes y exclusión social (Valenzuela, 2012). El juvenicidio se constata a la luz de los que hemos vivido y después de haber redefinido la mirada sobre tanta muerte, y haber constatado gran parte de los 150 mil muertos y desaparecidos desde el gobierno de Felipe Calderón y el enorme peso que tienen los jóvenes como parte de esos muertos; al observar la falta de respeto a la vida de estos muchachos, estudiantes normalistas de Ayotzinapa y la criminalización de los estudiantes, como lo vimos en el 68; al observar cómo se han ampliado los espacios de criminalización de los jóvenes; al ver cómo el crimen organizado practica una red de exterminio con mucha muerte de jóvenes cuyas muertes no son esclarecidas y ellos quedan en un inaceptable campo de sospecha.

Lo que queda como certeza es que hemos vivido demasiada muerte innecesaria de jóvenes que no debieron haber muerto. Estamos en una sociedad que no ha sido capaz de responder frente a la situación tan dramática a la que nos condujo un Estado adulterado que ha sido cómplice de la violencia y la muerte. Queda claro que el tema del juvenicidio es un eje fundamental para entender la obliteración de los procesos de vida juvenil y los grandes problemas estructurales de América Latina. Esto se fortalece muy claramente a raíz de lo que conversamos sobre tu propia perspectiva y la experiencia latinoamericana, con la muerte de más de 30 mil personas en Argentina; más de cinco mil asesinados por Pinochet durante su dictadura; los muertos de las políticas de tierra arrasada en Guatemala; la enorme cantidad de migrantes muertos con la Operación Guardia en el noroeste mexicano; los falsos positivos en Colombia; o el caso brasileño que constaté en el libro Vida de barro duro, con la muerte artera de jóvenes en las favelas, principalmente jóvenes afrobrasileños.

Necesitamos cruzar miradas, voces e interpretaciones para repensar de una manera más amplia el significado de lo que ha sido esa experiencia ominosa del juvenicidio en América Latina y sus conexiones transatlánticas que seguramente ameritan que, por lo menos, hagamos un trabajo conjunto. Uno no lo ve tan claro, pero al paso de los años tenemos una experiencia acumulada y una necesidad social de entender lo que estamos viviendo (como lo ocurrido en Ayotzinapa). Necesitamos ir más allá de la necesaria condición del duelo y el coraje, que son muy importantes, pero también tenemos que generar lazos interpretativos para darles sentido a las resistencias y construir nuevas formas de acción; tú lo dijiste de forma correcta: necesitamos construir esos conocimientos que nos ayuden a tener mejores prácticas, mejores intervenciones y mejores apuestas políticas. 


\section{Otro texto marcante en mi biografía}

C. F.: Tres preguntas para acabar. Primero, ¿cuáles han sido tus influencias teóricas?

J. M. V.: Bueno, por supuesto el tema del marxismo. Yo vengo de la vertiente trotskista, lo cual celebro mucho, porque la escena que teníamos se conformaba con posiciones de estalinistas, maoístas, que pintaban esculturas escribiendo: «Ningún intelectual y ningún artista le llega a los dedos de los pies a un obrero». Se prohibía a Honorato de Balzac y a Beethoven, por pequeñoburgueses; llevaron al suicidio a Maiakovsky. Todo ese proceso de muerte, de autoritarismo, un realismo y un arte proletario subordinado al código político. Y bueno, por otro lado Trotski escribía el Manifiesto Surrealista con André Bretón; eso marcaba una perspectiva muy diferente. Entonces fui formado en ese posicionamiento de lucha contra el capitalismo y contra la burocracia de la Unión Soviética; esa burocracia que había expropiado el poder político a la clase trabajadora. Mis otras influencias teóricas tienen que ver con el pensamiento sociológico y antropológico latinoamericano, eso fue muy importante.

Por otro lado, La sociedad de las esquinas de William Foote Whyte, fue un importante apoyo para mi trabajo sobre el cholismo; además de la impronta gramsciana que ya señalamos. En ese momento mis lecturas correspondían a las perspectivas de un marxismo crítico, primero con la Escuela de Frankfurt y lo que era el debate de Benjamín, Adorno, Horkheimer, Marcuse, Erich Fromm y Habermas y después me interesó mucho la obra de la Escuela de Birmingham, particularmente Raymond Williams (E. P.) Thompson, Stuart Hall, Richard Hoggart, etc.; esa podría ser la genealogía, pero para mí los estudios culturales no solo abrevan de Birmingham, sino que existe una tradición de pensamiento de materialismo cultural y anticolonial en América Latina, de lo cual yo me siento parte, e incluye a autores muy importantes como José Enrique Rodó, José Martí, José Carlos Mariátegui, el Ché Guevara, el colonialismo interno, los dependentistas, etc.

Bourdieu, por supuesto, es una influencia, pero mi primera formación viene de un campo ajeno al académico. Entonces a estos autores yo los leía desde el lente político-cultural y me siento muy afortunado por eso, porque creo que fueron lecturas marcantes, muy importantes. Y, bueno, a nivel anecdótico, cuando salió el libro ¡A la brava! estaba yo en la ciudad de Tijuana y tocan a la puerta y entra un joven pelirrojo sumamente simpático, con una risa estruendosa y un español que obviamente indicaba que no era su primera lengua, era estadounidense, y me dijo: «Mi, nombre es Marcus y mi mentor, Frederick Jameson, me envía para hacerle una invitación a Duke University». Me comentó que habían encontrado jA la brava ése! en una biblioteca en Alemania; entonces fui a Duke y participé en una reunión muy interesante, pues allí se encontraba el principal centro de estudios culturales de Estados Unidos; ahí estaba Frederick 
Jameson, Ariel Dorfman, Walter Mignolo, Alberto Moreiras, Larry Herzog; había un grupo muy importante.

Desde el inicio de mi actividad, realicé un trabajo de acompañamiento directo con las personas. Podría decir que gran parte de mis trabajos investigativos poseen un fuerte soporte etnográfico. Otras influencias importantes en mi carrera son Carlos Monsiváis, por supuesto; para mí su amistad y su trabajo fueron siempre una inspiración; Guillermo Bonfil, a quien conocí muy bien con su México profundo (1990) y me invitó a formar parte del Seminario de Estudios de la Cultura que él coordinaba; Néstor García Canclini, quien, por cierto, fue a Tijuana para hacer su trabajo Tijuana: la casa de toda la gente (1989), ahí fue cuando yo lo conocí y me pidió leer su primer borrador de Culturas híbridas (1990) y hacerle comentarios, lo cual considero un gran honor; Gilberto Giménez, extraordinario sociólogo de la cultura y las identidades sociales, además de amigo generoso; Jesús Martín Barbero, con quien he coincidido en algunas ocasiones y he tenido conversaciones muy amenas, aunque poco frecuentes - la vida es así-, pero su trabajo De los medios a las mediaciones (1987), fue otro texto importante en mi biografía intelectual; y Jorge Bustamante, pionero en los estudios de migración y fundador de El Colegio de la Frontera Norte; Después de esto, puedo decir que parte central de mis influencias intelectuales está en lo que han sido mis propias redes de amigos y colegas dentro del campo de estudios de la juventud.

C. F.: Y tus aportaciones teóricas, no podemos explicarlas todas, ya has explicado el juvenicidio, pero selecciona una que crees que es interesante, y qué sigue.

J. M. V.: Trabajé mucho el tema de identidades sociales, muy influido por Gilberto Giménez, apropiándome y recreando conceptos sobre las identidades sociales para pensar las identidades juveniles como expresiones situadas, racionales, cambiantes, con reconocimiento en el tiempo; conformadas en la disputa de la auto y la heteropercepción, cambiantes, articuladas con otros repertorios identitarios, y pensamos a la juventud como relación social inscrita en campos de poder y, por tanto, la disputa por los sentidos de lo juvenil también se inscribe en el campo de la disputa política. También trabajé los conceptos de tiempo social e intensidad del tiempo social para comprender la inscripción del tiempo en los territorios corporales, el presentismo juvenil, la narcocultura, la biocultura con los ejes de biocultura de Foucault, Agamben, Heller y otros, pero desarrollando los conceptos de la significación y expresión de los cuerpos como dispositivos que confrontan a la biopolítica desde las biorresistencias, bioproxemia, bioidentidad y los biotaratos. 


\section{Esos cambios nos hablan de otro tipo de sujetos juveniles}

C. F.: Empezaste a investigar la juventud hace 35 años, si no me equivoco, ¿cómo ves el cambio de la juventud y las culturas juveniles en este periodo entre antes y ahora?

J. M. V.: Sí, en el 81 desde el campo militante y como investigador desde el 82 . Creo que los cambios más importantes que observo pasan por las maneras como se construye el sentido de adscripción, de pertenencia y de significar lo juvenil. Yo creo que los grandes cambios tampoco se inscriben en la redefinición de la forma subalternizada de los jóvenes, pues permanece el control autocrático; pero creo que los grandes cambios pasan por la conformación de los estilos juveniles, por la mediación de las nuevas tecnologías y por la reaparición de las y los jóvenes como protagonistas de los grandes movimientos sociales alrededor del mundo, desde 2010 a la fecha. Ahí está la primavera árabe en Egipto, el movimiento Occupy, el de los Dreamers y Black Lives Matter en Estados Unidos, el yo soy 132 en México, la Mane colombiana, la Asociación Nacional de Estudiantes Chilena, el pase libre, la revuelta brasileña y el movimiento de las periferias en Brasil, además de las importantes manifestaciones recientes en Chile con el apruebo, en Colombia, frente a la violencia y el autoritarismo, en Bolivia, contra el golpe militar, en Panamá, frente a la indolencia social del gobierno.

Aunque hay una fuerte territorialización de ciertos grupos, también vemos jóvenes que no buscan el control del territorio sino su significación; esto es muy claro en el tema del grafiti y en las experiencias de intervención urbana. Ya no es solo el tema del control territorializado y la vigilancia, sino la disputa por la significación del espacio público y de la ciudad que genera otro tipo de rutinas y algunos, como los punk, han sido nómadas urbanos que viajan por la ciudad y que no les interesa un control de territorio. Entonces yo pienso que esos cambios nos hablan de otro tipo de sujetos juveniles, mucho más informados en muchos sentidos, también mucho más desencantados. Cuando yo inicié mi trabajo de investigación, iniciando los años ochenta, era la década perdida, se vivían desesperanzas muy fuertes en muchos lugares de América Latina. En un recorrido que llegamos a hacer con nuestros amigos Alonso y Marta Salazar, en Medellín, la ciudad más violenta del mundo, había una situación encapsulada entre las comunas con fronteras invisibles. En Brasil, cuando ingresé a algunas favelas, me sorprendió, al presentar una conferencia en la universidad, que la mayoría de los asistentes no conocían las favelas.

C. F.: Última pregunta: partiendo del título de tu libro El futuro ya fue (Valenzuela, 2009), ¿cómo lo aplicarías al futuro de los jóvenes o de los estudios de juventud?, ¿cuáles serán los retos? 
J. M. V.: Yo pienso que cada vez que se da más fuerte la disputa y transgresión de las disciplinas académicas y el crecimiento de posicionamientos muy transfronterizos, las crisis de las fronteras; esta frontera donde es difícil seguir pensando desde una historia que, como bien lo plantea Michel de Certeau, el historiador no es el buscador de datos sino constructor de significados o, como planteaba Braudel, cuando el historiador comienza a escudriñar los procesos sociales invade el campo de la sociología. Igual, cuando los sociólogos trabajan procesos, se acercan o se colocan en el terreno de la historia. Podemos ver también la crisis desde una perspectiva etnográfica, en donde seguir pensando una antropología claramente construida desde una impronta colonizadora. Malinowski palidece al sostener el estar ahí como criterio de verdad, de la autoría difusa, de la exotización del otro, del ventriloquismo; eso se desdibuja, como afirmaba Clifford Geertz. Yo tengo un texto que se llama La carpa sobre el asfalto (Valenzuela, 2005), donde reflexiono sobre el investigador implicado en los procesos sociales que estudia. El discurso académico ha perdido centralidad como el discurso legitimado del saber-poder; ahora vemos otras narrativas y otros discursos surgidos de los propios jóvenes o los discursos erosionados y deslegitimados de la televisión frente a las o de las redes sociales. Me gusta mucho la transformación del campo de los estudiosos de juventud, donde cada vez más recurren a polifonías narrativas y a la incorporación de múltiples formas textuales de lo visual, de lo sonoro, de la revisión teórica e incorporación de la literatura, como un Carles Feixa que se convirtió en un mago de la metáfora para entender a los movimientos juveniles. Todas estas son transformaciones muy importantes y veo una suerte de desdibujamiento del papel de la autoridad de la academia y de su capacidad de construcción de interpretaciones y narrativas sobre los jóvenes frente a perspectivas mucho más dialógicas con las propias construcciones de los jóvenes sobre sí mismos y sobre los otros mundos. Creo que las y los jóvenes tendrán la capacidad para construir un mundo mejor, un mundo menos injusto, más igual, un mundo que sí es posible, a pesar de que vemos crecer las tentaciones autoritarias de quienes tienen el poder y se afanan en degradar la vida, la habitabilidad y la naturaleza. Tenemos dos grandes responsabilidades, nos dice Stuart Hall aludiendo a Gramsci: la primera, es producir el mejor conocimiento y, la segunda, socializarlo, garantizar que llegue a las grandes mayorías.

C. F.: Espero que a través de esta entrevista se socialice. Y una última dedicatoria: tú tienes una persona que te ayuda en este viaje, tu hijo Pavel, ¿cierto?

J. M. V.: El trabajo con Pavel ha sido algo maravilloso, porque él se formó en antropología visual en Barcelona, España. Se interesó en los discursos visuales y, posteriormente, se ha dedicado a la elaboración de videodocumentales y videoetnografía. Hemos realizado un trabajo conjunto donde yo he pasado a segundo plano. Él hace cosas muy serias, muy profesionales, 
pero aquí la parte más interesante es que hemos articulado el trabajo de campo, la etnografía, que es videograbada. Realizamos un trabajo etnográfico con un sentido distinto definido por la mediación del videodocumental. En algunos de estos proyectos también nos ha acompañado mi hija Danae, quien se especializó en Estudios Latinomericanos y en Literatura. Ella ha realizado un trabajo de investigación con migrantes centroamericanos en su paso por México y sobre prácticas culturales de los migrantes haitianos que se encuentran en Santiago de Chile y en Tijuana, México.

\section{Epílogo (noviembre de 2020)}

C. F.: José Manuel, esta entrevista la mantuvimos hace seis años. Me gustaría que pudieras completar lo sucedido desde entonces, sobre todo en dos campos. Por una parte, la evolución y maduración del estudio del juvenicidio, que tuvo como su máxima expresión el libro que coordinaste a partir del encuentro de Manizales (Valenzuela, 2015) y tu última publicación sobre el tema (Valenzuela, 2019), tema en el que nos acabamos de reencontrar en línea con la red que se generó entonces, y que ha tenido como principal resultado el Diplomado en Juvenicidio de El Colef, que va por la cuarta edición. Por otra parte, el impacto terrible de la pandemia en México y, más allá, cómo afecta a la juventud y al juvenicidio (como hemos visto recientemente en Colombia).

J. M. V.: Vivimos tiempos aciagos, tiempos de pandemia, de dolor, de confinamiento, de ausencia, de muerte artera, muerte fulgurante. Millones de infectados y cientos de miles de personas fallecidas se apilan con una crisis económica mundial que se profundiza. La pandemia expresa las enormes debilidades, desigualdades y mezquindad del capitalismo neoliberal; exhibe la precarización de las condiciones de salud y de la vida. Covid or not Covid, esa es la cuestión que incide en el entramado humano y define los umbrales entre vida y muerte. Las y los jóvenes han recibido una suerte de «bono sanitario» al tener tasas mucho más bajas de letalidad que otros grupos, especialmente de los que se ubican en la llamada tercera edad; pero también están pagando un abono económico al ser de los sectores más golpeados por la obliteración de los canales para desarrollar proyectos viables y vivibles de vida. Son ellos a quienes corresponde principalmente remontar las condiciones de adversidad económica y social acentuadas por la pandemia en un escenario que no luce nada promisorio.

Al mismo tiempo, la violencia sigue siendo la principal causa de muerte de jóvenes en América Latina. Violencias estructurales (estructuradas y estructurantes) que delimitan los rasgos de las necrozonas sociales definidas por la precarización económica, social, cultural, laboral, urbana y simbólica; sistemas de procuración de justicia que traicionan su propio nombre, 
migraciones y desplazamientos forzados plagados de violencia, ataques, extorciones, violaciones y agresiones sexuales; el deterioro de los políticos y de la política conformada desde la relación Estado y sistema de partidos, la fractura del marco axiológico por procesos profundos de corrupción, sevicia y avaricia de quienes deberían tener un papel central como referentes éticos. En estos escenarios permanece y se alimenta el juvenicidio, concepto que se ha instalado de manera amplia en la reflexión socioantropológica de América Latina y de otros lugares. Nadie puede alegrarse de que esto ocurra, pero debemos entender la atingencia académica y social de un concepto que nos ayuda a pensar y luchar frente a la muerte artera sobre las iuvenis sacer. El juvenicidio ha sido un dispositivo teórico que nos permite tener una mejor comprensión sobre los contextos que generan las condiciones de precarización y vulnerabilidad que tapizan a las necrozonas y construir estrategias políticas y bioculturales para evitar que eso siga ocurriendo. El juvenicidio, como el feminicidio, son conceptos que deconstruyen los dispositivos de muerte y permiten la articulación de luchas políticas, culturales, legales y simbólicas que buscan el respeto a la vida, a los derechos humanos y a las condiciones para la construcción de vidas dignas, vidas vivibles, vidas felices.

\section{Referencias}

Bonfil, G. (1990). México profundo. Consejo Nacional para la Cultura y las Artes.

García-Canclini, N. (1989). Culturas Híbridas. Consejo Nacional para la Cultura y las Artes. García-Canclini, N. (1989). Tijuana: la casa de toda la gente. Instituto Nacional de Antropología e Historia; Escuela Nacional de Antropología e Historia.

García-Robles, J. (1985). ¿Qué transa con las bandas? Posada.

Martín-Barbero, J. (1987). De los medios a las mediaciones. Gustavo Gili.

Valenzuela, J. M. (1988). ¡A la brava ése! Cholos, punks, chavos banda. El Colegio de la Frontera

Norte [1998, $2^{\underline{a}}$ ed. corregida y aumentada].

Valenzuela, J. M. (1991). Empapados de sereno: el movimiento urbano-popular en Baja California, 1928-1988. El Colegio de la Frontera Norte.

Valenzuela, J. M. (1997). Vida de barro duro: cultura popular y graffiti. El Colegio de la Frontera Norte.

Valenzuela, J. M. (1998). El color de las sombras: chicanos, identidad y racismo. El Colegio de la Frontera Norte.

Valenzuela, J. M. (1998b). Nuestros piensos: culturas populares de la frontera México-Estados Unidos. Consejo Nacional para la Cultura y las Artes. 
Valenzuela, J. M. (2002). Jefe de jefes: corridos y narcocultura en México. Plaza y Janés; Raya en el Agua.

Valenzuela, J. M. (2002b). De los pachucos a los cholos: movimientos juveniles en la frontera México-Estados Unidos. En C. Feixa, F. Molina \& C. Alsinet (Eds.), Movimientos juveniles en América Latina: pachucos, malandros, punketas (pp. 11-34). Ariel.

Valenzuela, J. M. (2004). Paso del Nortec. Trilce.

Valenzuela, J. M. (2005). La carpa sobre el asfalto. En N. García-Canclini (Ed.), La antropología urbana en México. Fondo de Cultura Económica.

Valenzuela, J. M. (2009). El futuro ya fue: socioantropología de los jóvenes en la modernidad. El Colegio de la Frontera Norte.

Valenzuela, J. M. (2012). Sed de mal: feminicidio, jóvenes y exclusión social. El Colegio de la Frontera Norte.

Valenzuela, J. M. (2014). Transfronteras: fronteras del mundo y procesos culturales. El Colegio de la Frontera Norte.

Valenzuela, J. M. (2017). Precariedades, exclusiones y emergencias: necropolítica y sociedad civil en América Latina. Gedisa.

Valenzuela, J. M. (2019). Trazos de sangre y fuego: bionecropolítica y juvenicidio en América Latina. Calas.

Valenzuela, J. M. (Ed.). (2014). Tropeles juveniles: culturas e identidades (trans)fronterizas. El Colegio de la Frontera Norte.

Valenzuela, J. M. (Ed.). (2015). Juvenicidio. Ayotzinapa y las vidas precarias en América Latina y España. NED Ediciones, El Colegio de la Frontera Norte, Universidad Jesuita de Guadalajara.

Valenzuela, J. M. (Ed.). (2015b). El sistema es antinosotros: culturas, movimientos y resistencias juveniles. Gedisa.

Valenzuela, J. M., \& González, G. (Eds.) (1999). Oye cómo va: recuento del rock tijuanense. Instituto Mexicano de la Juventud.

Valenzuela, J. M., \& Sánchez, J. (Jofras) (2012). Welcome amigos to Tijuana: graffiti en la frontera. Editorial RM.

Valenzuela, J. M., Nateras, A., \& Reguilo, R. (Eds). (2007). Las maras: identidades juveniles al límite. Universidad Autónoma Metropolitana. 